\title{
LA-UR $=94-3000$
}

Conf-9407103--31

Los Alamos National Laboratory is operated by the University of California for the United States Department of Energy under contract W-7405-ENG-36

TITLE: A Small Scale Accelerator Driven Subcritical Assembly Development and Demonstration Experiment at LAMPF

AUTHOR(S): Stephen A. Wender, Francesco Venneri, Charles D. Bowman, Edward D. Arthur, Edward A. Heighway, Carl A. Beard, Roger R. Bracht, John J. Buksa, Walter Chavez, Barbara G. DeVolder, John J. Park, Ronald B. Parker, Chandra Pillai, Eric J. Pitcher, Robert C. Potter, Robert S. Reid, Gary J. Russell, David A. Trujillo, Joseph Balderas, Daniel J. Weinacht, William B. Wilson, and Keith A. Woloshun

SUBMITTED TO: International Conference on Accelerator-Driven Transmutation Technologies and Applications

Las Vegas, NV

July 25-29, 1994

By acceptance of this article, the publisher recognizes that the U.S. Government retains a non-exclusive, royalty-free license to publish or reproduce the published form of this contribution, or to allow others to do so, for U.S. Government purposes.

The Los Alamos National Laboratory requests that the publisher identify this article as work performed under the auspices of the U.S. Department of Energy.

\section{LOS ADMOS}

Los Alamos National Laboratory

Los Alamos, New Mexico 87545
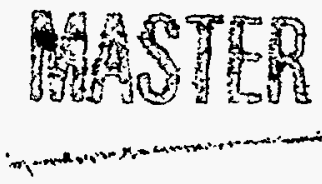

DIGTFRUTIOU OF THIS DOCLAENT FE UNL RGTED 


\section{DISCLAIMER}

This report was prepared as an account of work sponsored by an agency of the United States Government. Neither the United States Government nor any agency thereof, nor any of their employees, make any warranty, express or implied, or assumes any legal liability or responsibility for the accuracy, completeness, or usefulness of any information, apparatus, product, or process disclosed, or represents that its use would not infringe privately owned rights. Reference herein to any specific commercial product, process, or service by trade name, trademark, manufacturer, or otherwise does not necessarily constitute or imply its endorsement, recommendation, or favoring by the United States Government or any agency thereof. The views and opinions of authors expressed herein do not necessarily state or reflect those of the United States Government or any agency thereof. 


\section{DISCLAIMER}

Portions of this document may be illegible in electronic image products. Images are produced from the best available original document. 


\title{
A Small Scale Accelerator Driven Subcritical Assembly Development and Demonstration Experiment at LAMPF
}

S. A. Wender, F. Venneri, C. D. Bowman, E. D. Arthur, E. Heighway C. A. Beard, R. R. Bracht, J. J. Buksa, W. Chavez, B. G. DeVolder, J. J. Park, R. B. Parker, C. Pillai, E. Pitcher, R.C. Potter, R. S. Reid, G. J. Russell, D. A. Trujillo, D. J. Weinacht, W. B. Wilson, K. A. Woloshun

Los Alamos National Laboratory

Los Alamos, NM 87545

\begin{abstract}
A small scale experiment is described that will demonstrate many of the aspects of accelerator-driven transmutation technology. This experiment uses the high-power proton beam from the Los Alamos Meson Physics Facility accelerator and will be located in the Area-A experimental hall. Beam currents of up to $1 \mathrm{~mA}$ will be used to produce neutrons with a molten lead target. The target is surrounded by a molten salt and graphite moderator blanket. Fissionable material can be added to the molten salt to demonstrate plutonium burning or transmutation of commercial spent fuel or energy production from thorium. The experiment will be operated at power levels up to $5 \mathrm{MW}_{\mathrm{t}}$.
\end{abstract}

\section{Introduction}

The coupling of a neutron producing accelerator with a sub-critical fission assembly has been proposed at Los Alamos as a method of addressing several issues of current importance. This type of subcritical system can be operated in a much larger parameter space than an ordinary reactor. Because of this increased flexibility in operating conditions, an accelerator driven subcritical fission system can be used to 1) destroy weapons grade plutonium with little actinide residue, 2) burn spent fuel from commercial reactors with reduced waste stream and 3) generate power using the thorium/uranium cycle. Because the fuel does not need to be enriched, it appears that the system can be made more proliferation resistant than other proposed systems that address these issues.

At present the system concept for an accelerator driven transmutation technology (ADTT) system consists of a $500 \mathrm{MW}_{\mathrm{t}}$ module driven with $15 \mathrm{~mA}$ of $800 \mathrm{MeV}$ proton 
beam (12MW) incident on a neutron production target. The neutron production target is at the center of a LiF-BeF 2 molten salt (MS) and graphite moderator blanket. In the case of plutonium destruction, plutonium can be added to the molten salt. Other applications such as energy production (EP) and accelerator transmutation of waste (ATW) will probably use the same basic technology and design philosophy. In these cases thorium or spent fuel could be added to the molten salt to demonstrate energy production or spent fuel transmutation.

Considerable knowledge and experience exists on the operation of MS systems from the Molten Salt Reactor Experiment (MSRE) that was operated at the Oak Ridge National Laboratory (ORNL) in the 1960's. At the conclusion of the MSRE, the researchers at ORNL felt that they had satisfactorily demonstrated the basic requirements of MS operation. In the design of this experiment we have assumed that the major technical issues have been satisfactorily addressed by this work at ORNL. As we design and fabricate the experiment, we will continuously evaluate the technology and update it where possible or necessary.

As a crucial step towards developing a $500 \mathrm{MW}_{\mathrm{t}}$ prototype module, we are proposing a small scale demonstration experiment. The experiment consists of a phased sequence of development and demonstration activities that begin with the development of a molten-lead target and techniques for molten salt handling. The experiment will culminate in the operation of an integrated accelerator-target/blanket subcritical fission assembly that can operate at power levels of up to $20 \mathrm{MW}_{\mathrm{t}}$, although significant progress can be made at lower power levels.

This experiment will demonstrate many of the important aspects of ADTT and will be modeled on the preconceptual design of a single $500 \mathrm{MW}_{\mathrm{t}}$ module. The experiment will take advantage of the high power $800 \mathrm{MeV}$ proton beam from the Los Alamos Meson Physics Facility (LAMPF) accelerator and will be located in experimental Area-A. Proton beam currents of up to $1 \mathrm{~mA}(800 \mathrm{~kW})$ will be incident on the neutron production target. The experiment has the following ultimate goals:

1. It will demonstrate the integrated operation of a high-power particle beam used to produce neutrons coupled to a subcritical fission assembly. The power levels will be high enough to show significant transmutation processes.

2. It will test the analytical, diagnostic and control instrumentation that will be developed to monitor and operate the system. It will verify predicted system responses, time constants and reactivity behavior of the integrated system.

3. It will demonstrate the operation and performance of the neutron production target both alone and coupled to the molten salt blanket. It will also demonstrate the beam window technology necessary to inject the beam into such a target.

4. It will demonstrate techniques for large scale molten salt handling. It will provide a test bed for gaining safety related experience in molten salt operations. 
5. It will demonstrate control of molten salt chemistry, material solubilities, material deposition and plate out problems.

6. It will demonstrate the helium sparging techniques for handling and removing the evolved fission product gases and the containment of tritium.

7. At a reduced flux level, it will verify the integrity of the materials and the design concepts used.

8. It will demonstrate the control of environment, safety and health (ES\&H) issues related to the operation of the integrated system.

\section{Molten Lead Target}

The neutron production target consists of a cylindrical container that holds the molten lead, a lead-to-helium heat exchanger that is located above this cylinder and a reservoir below the target volume. A window on the side of the target allows the proton beam to enter the target volume and internal baffling directs the flow of the lead against the window to ensure proper cooling. A liquid lead target provides the following advantages:

1. Higher beam powers can be used compared to solid targets. The beam power in solid targets is limited by the ability to cool them. This limits the beam power to approximately $1 \mathrm{MW}$. Many ADTT concepts as well as spallation targets for material science research involve power levels substantially greater than $1 \mathrm{MW}$. Development of this technology will have wide and future applications. Similar liquid lead targets are being developed at PSI for the SINQ spallation source.'

2. Because the bulk of the material is liquid, the target is not subject to the same radiation damage issues that are present in solid target designs. Radiation damage concerns are only present in the container and window of the target. In addition, the molten lead can removed and reused if the container needs to be replaced.

3. Because a liquid lead target does not have to be cooled by the salt it can be decoupled from the salt tank and physically isolated from it. This means the target can have its own container and can be removed without having to open up the salt volume that may contain highly radioactive and fissionable material. In addition, removal of the target will be much easier because its volume and mass are only small part of the salt blanket system. The tank that contains the molten salt does not require a window for the beam.

Two types of molten lead targets are possible: pure lead and lead-bismuth eutectic (LBE). LBE has the advantage of a lower melting point. LBE has a melting point of approximately $125^{\circ} \mathrm{C}$ which is considerable lower than the $325^{\circ} \mathrm{C}$ of pure lead. This 
reduced temperature will simplify some of the materials issues in the operation of the target. The major disadvantage of $\mathrm{LBE}$ is that the production of radioactive $\mathrm{Po}$ is approximately 1000 times greater than that of molten lead. ${ }^{2}$ We are presently evaluating the choice of lead for this target.

Figure 1 shows a schematic drawing of the liquid lead target. A detailed description of the target design and operation is given by the Beard et. al ${ }^{3}$ in this conference. The present choice of a material for the target container is $\mathrm{Nb}$ with $1 \% \mathrm{Zr}$. This choice is based on its excellent compatibility with molten lead and is discussed in a contribution by Park et. $\mathrm{al}^{4}$ in this conference.

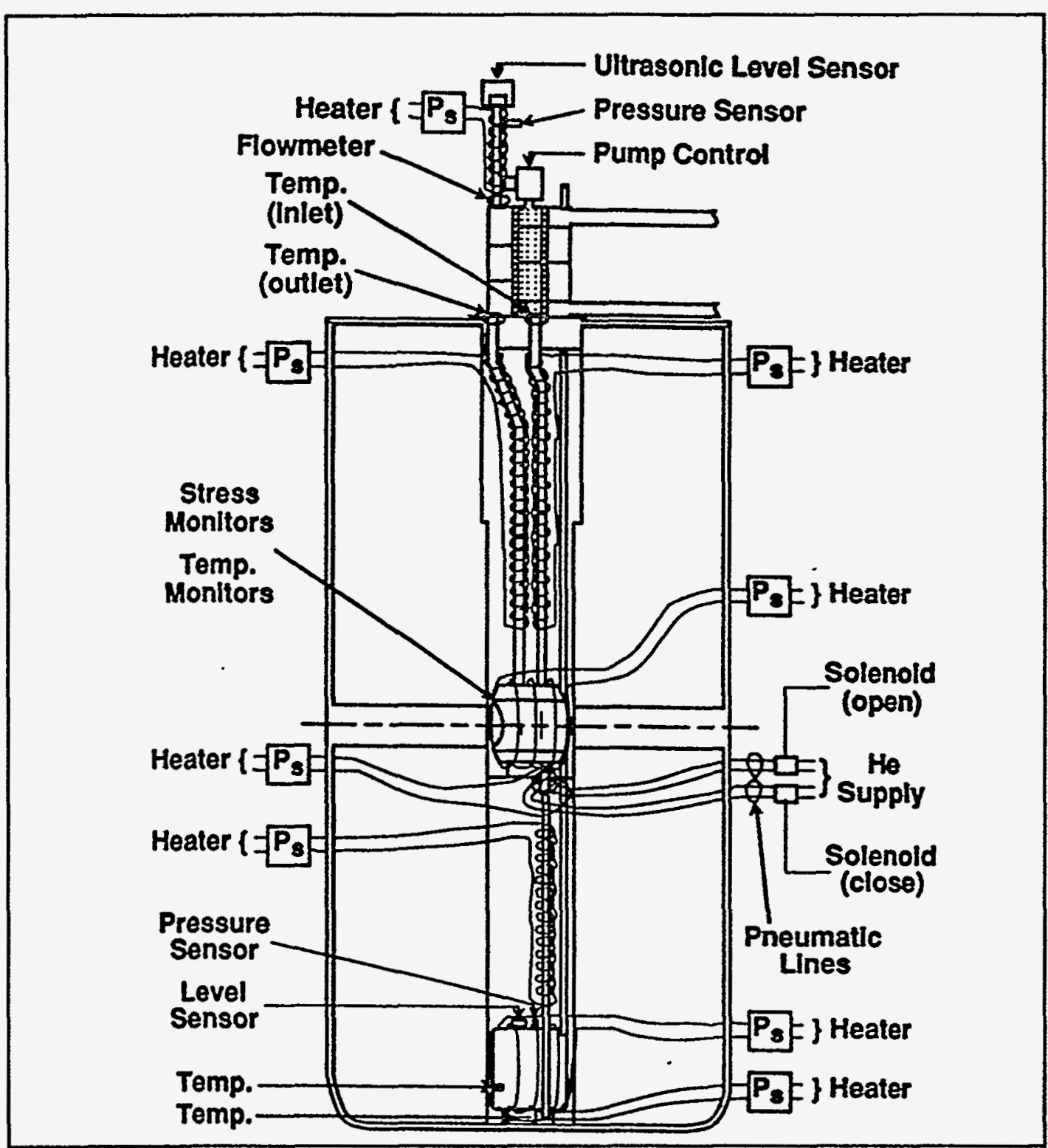

Figure 1. Drawing of the molten lead target for the accelerator driven subcritical assembly 
The lead is stored in a reservoir below the target volume when not being irradiated. Lead is pumped into the target volume with pressurized argon. During normal operation the valve between the reservoir and the target volume is closed and the lead circulates between the target volume and the heat exchanger. The lead is returned to the reservoir to cool and is stored there.

\section{Site Selection}

We chose to locate the experiment at the LAMPF accelerator because LAMPF presently has the highest beam power of any accelerator in the world and the beam energy is similar to that being proposed for the actual modules. A beam current of $1 \mathrm{~mA}$ is about the right intensity to test many of the issues associated with the development of the 500 $\mathrm{MW}_{\mathrm{t}}$ module and will not require significant expenditure that going to higher currents will require. The proposed location for the experiment is after the A1 and A2 pion production targets (between the A3 and A4 targets). This location was chosen for the following reasons:

1. The proton beam transport and shielding for up to $1 \mathrm{~mA}$ of beam already exists.

2. There is relatively easy access to the proton beamline through stackable shielding, with little or no modification of existing structures necessary.

3. Because this location has never been the site of a production target it is relatively unactivated.

4. There is a large area near the beamline to stage the experiment. This area can be used to set up the experiment prior to its placement in the beam. The support infrastructure such as cooling and electrical power that will be installed for these initial test can be used in the actual experiment.

5. There is good access to the experimental and setup areas with a large forklift and there is a 30 ton overhead crane in both the setup and the experimental areas.

\section{Molten Salt Blanket}

Figure 2 shows a conceptual design of the experimental tank for the experiment. It consists of a $3.6 \mathrm{~m}$ diam, $4.2 \mathrm{~m}$ high cylinder with a hole in the center for the target cell. The entire tank is fabricated from Hastelloy $\mathrm{N}$ and contains the molten $\mathrm{LiF}_{-} \mathrm{BeF}_{2}$ salt and an array of carbon moderators. Hastelloy $\mathrm{N}$ has been shown in the MSRE to have excellent compatibility with molten salt. The lithium in the salt will be enriched to $99.9 \%$ in ${ }^{7} \mathrm{Li}$ to reduce the absorption of neutrons due to of the large thermal capture cross section of ${ }^{6} \mathrm{Li}$. The beam passes through the tank and enters the molten lead target cell on the side through a window. The molten salt is heated to a temperature of 
approximately $600^{\circ} \mathrm{C}$ and is circulated through the carbon moderators and cooled by heat exchanges located inside the molten salt tank. An external cooling loop, that uses a NaF$\mathrm{LiF}$ molten salt with boron added cools the primary heat exchanger in the tank. The secondary loop is cooled by an independent heat exchanger. Some of the physical properties of the system are listed in table 1.

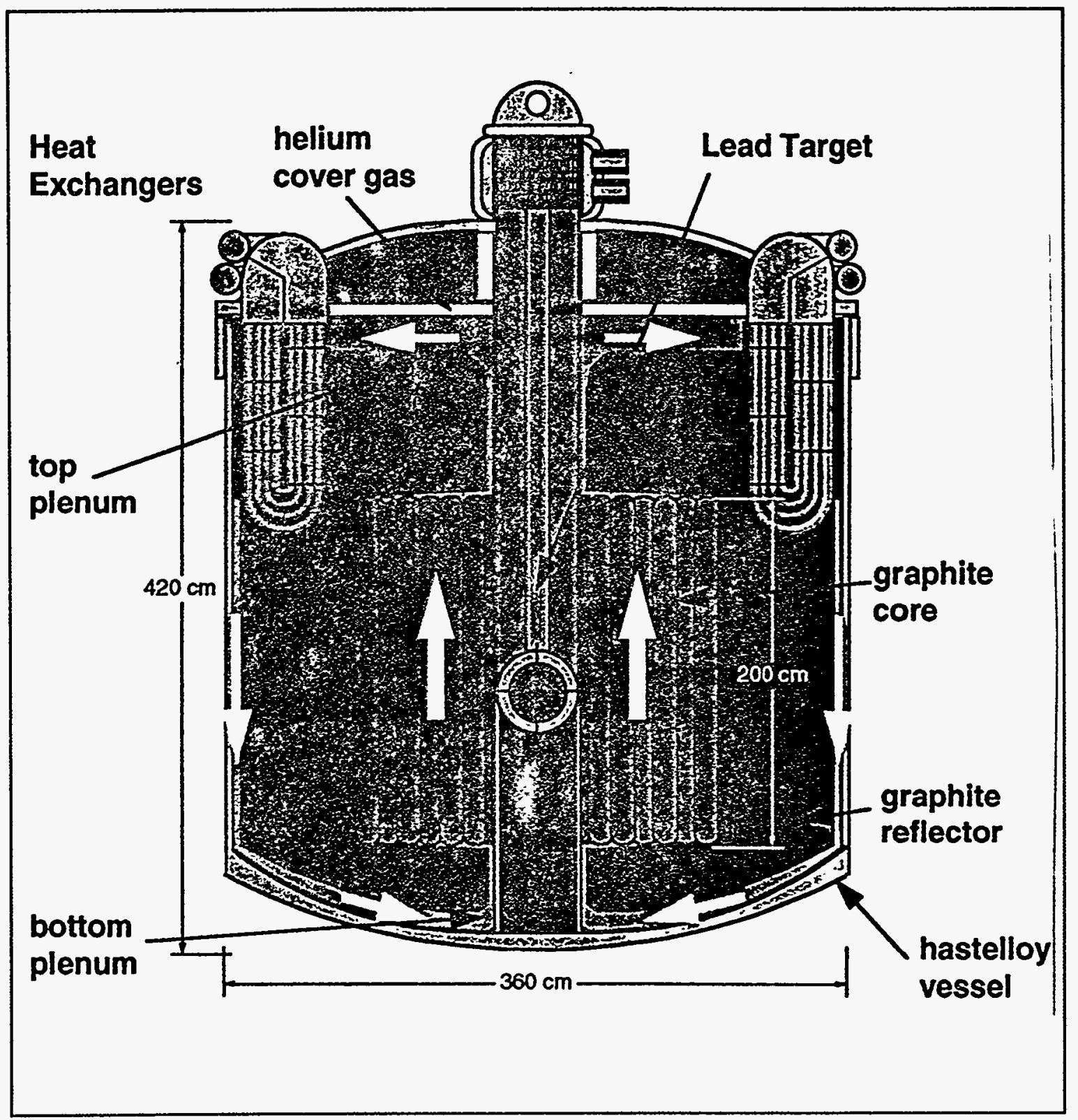

Figure 2. A conceptual system layout of the molten salt blanket for the accelerator driven subcritical assembly. 
Table I

Physical Properties of Experiment

$\begin{array}{ll}\text { Volume of salt } & 1 \mathrm{~m}^{3} \\ \text { Volume of carbon } & 10 \mathrm{~m}^{3} \\ \text { Operating temperature of salt } & 600^{\circ} \mathrm{C} \\ \text { Lead Target volume } & 60 l \\ \text { Operating temperature of target } & 500^{\circ} \mathrm{C}\end{array}$

There will be a small pipe installed in the tank to allow the removal of small amounts of salt during the experiment to monitor the oxidation state of the $\mathrm{Pu}$ and the build up of fission products (FP). Small amounts of material will be added to the sait blanket to adjust the redox potential of elements in the molten salt blanket. The control of the salt flow through this drain pipe will be via freeze plugs that have been used successfully in the MSRE. There will be provisions to supply approximately $1 \mathrm{MW}$ of electrical power to the MS tank to heat the salt during initial setup when there is no power being supplied by the beam.

\section{Experiment Schedule}

The experiment will proceed in three stages. The first stage involves the development of the molten lead target. In the second stage, the molten salt tank is constructed and the technology for molten salt operation is developed. In the final stage, fissionable material is added to the molten salt target/blanket and actual transmutation processes are demonstrated. In this stage, small amounts of fissionable material will be added and the response of the system will be measured. The measurements will be compared to the predicted behavior. If the calculations are verified, more fuel may be added to the blanket and the power increased.

At each stage, the systems will be developed first in off-line test stands. Following complete testing, each system will be installed in the LAMPF beamline and tested in-beam. For the case of the molten lead target, the radiation testing will occur at the LAMPF beam stop location. In the case of the molten salt tank, the testing will occur in the new target area in the location described in section III.

\section{System Performance}

We have calculated the performance of a fueled molten salt subcritical target blanket system based on the conceptual design of this experiment. Figures 3 and 4 shows calculations of initial blanket power and initial $k_{\text {eff }}$ following the addition of ${ }^{239} \mathrm{Pu}$ 


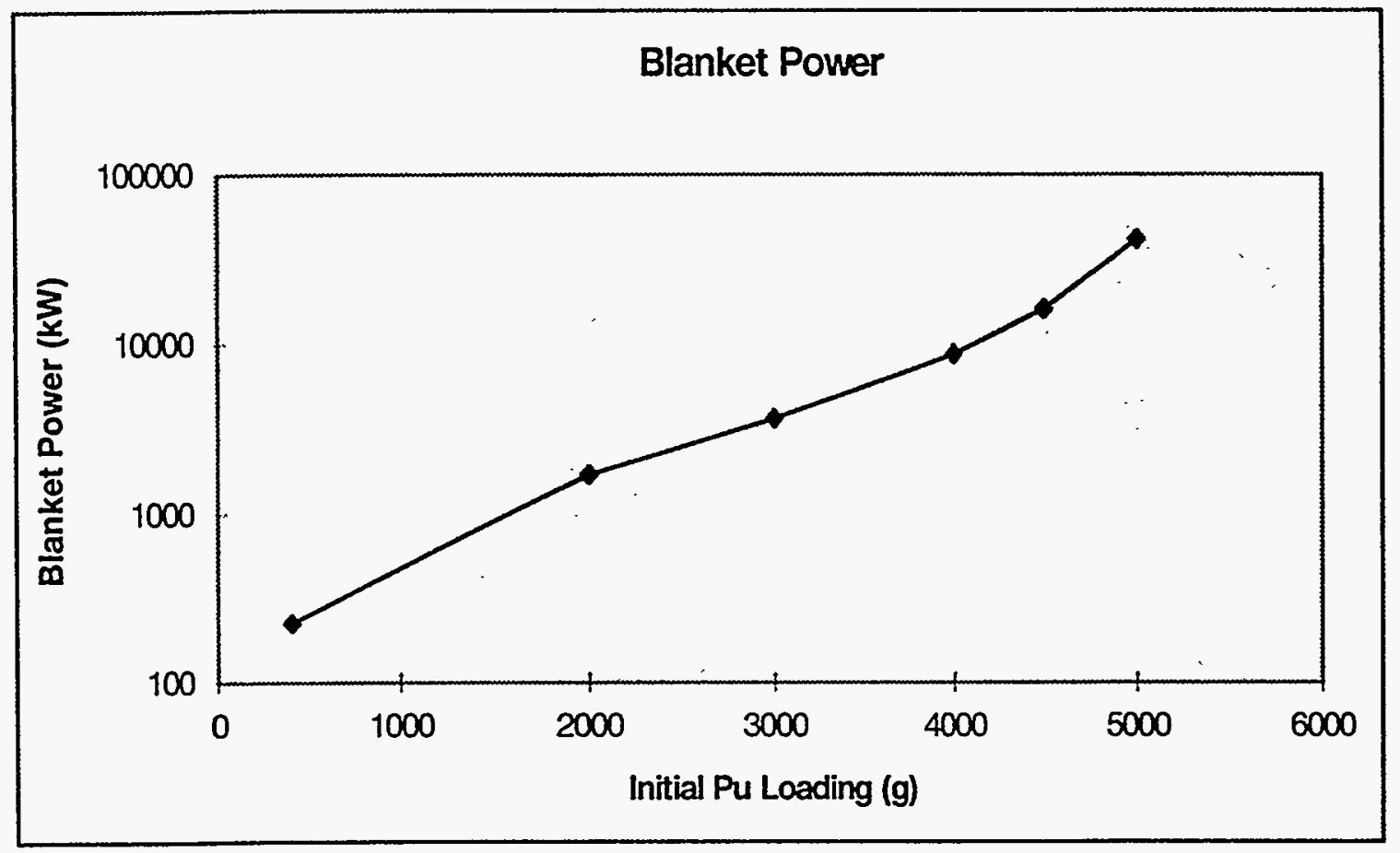

Figure 3. Initial blanket power for various initial plutonium loadings in the molten salt.

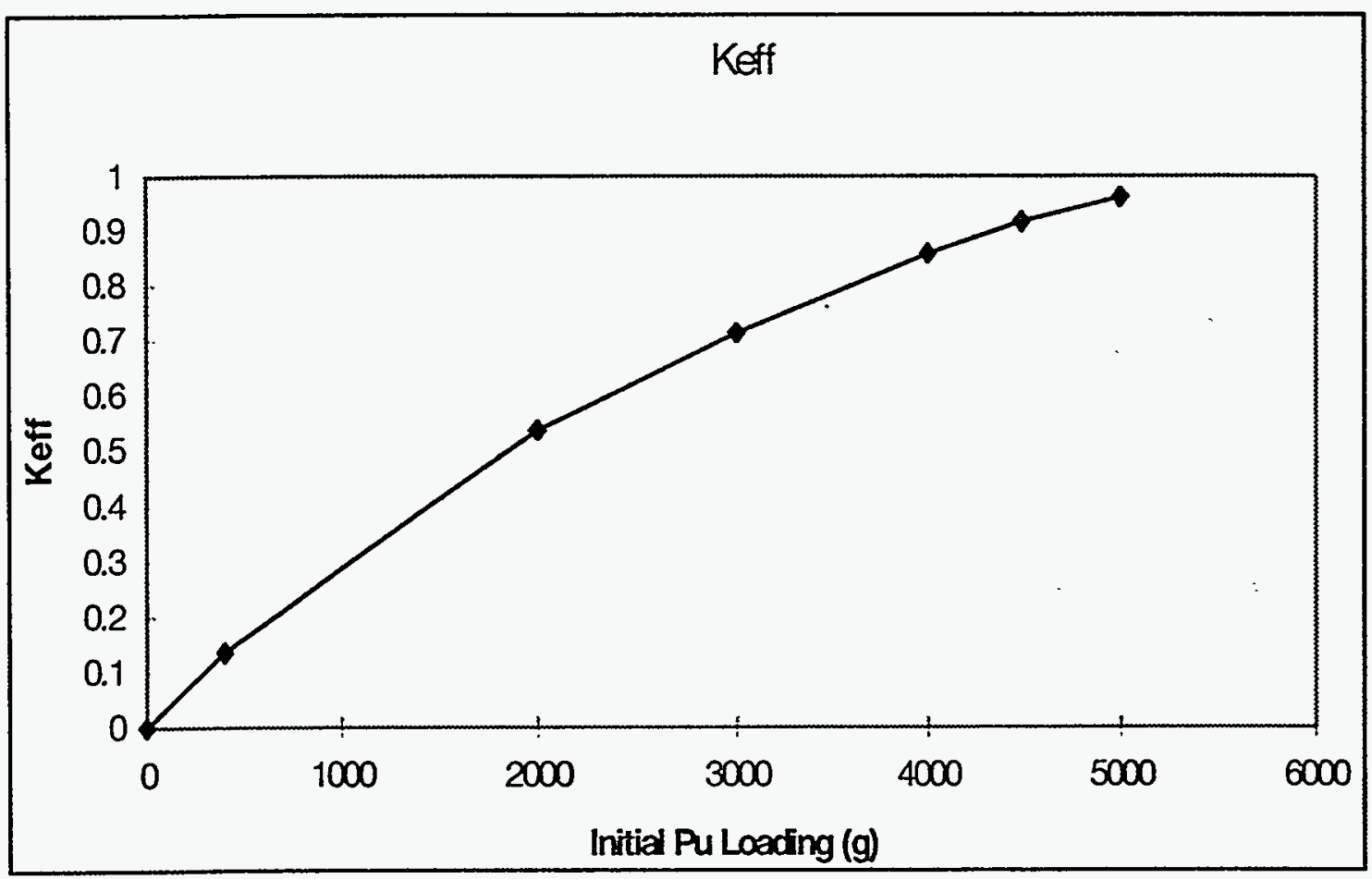

Figure 4 Initial $k_{\text {eff }}$ for different initial plutonium loading in the molten salt blanket. 
to the molten salt blanket. For these calculations we have assumed $1 \mathrm{~mA}$ of proton beam with a neutron production target that produces 21 neutron/proton. For an initial loading of $3 \mathrm{~kg}$ of ${ }^{239} \mathrm{Pu}$, the power in the blanket is calculated to be approximately $4 \mathrm{MW}$ and $\mathrm{k}_{\mathrm{efr}}$ is approximately 0.7 .

Energy production from thorium is shown in figure 5 . The solid squares show the time dependence of the blanket power when the MS blanket is loaded with $1000 \mathrm{~kg}$ of thorium. The open circles show the performance of the system for the case where $2 \mathrm{~kg}$ of ${ }^{239} \mathrm{Pu}$ is added to the $1000 \mathrm{~kg}$ of thorium. For comparison, the triangle curve shows the time dependence of the blanket when only $2 \mathrm{~kg}$ of pure ${ }^{239} \mathrm{Pu}$ is added. As seen from the figure (squares), the power from the fission of ${ }^{233} \mathrm{U}$ slowly rises when only thorium is used in the blanket. The power output and the breeding rate of ${ }^{233} \mathrm{U}$ can be increased with the addition of ${ }^{239} \mathrm{Pu}$. The fact that the curve for thorium and plutonium increase above the curve for pure plutonium is an indication of power generation using the thorium/uranium breeding cycle.

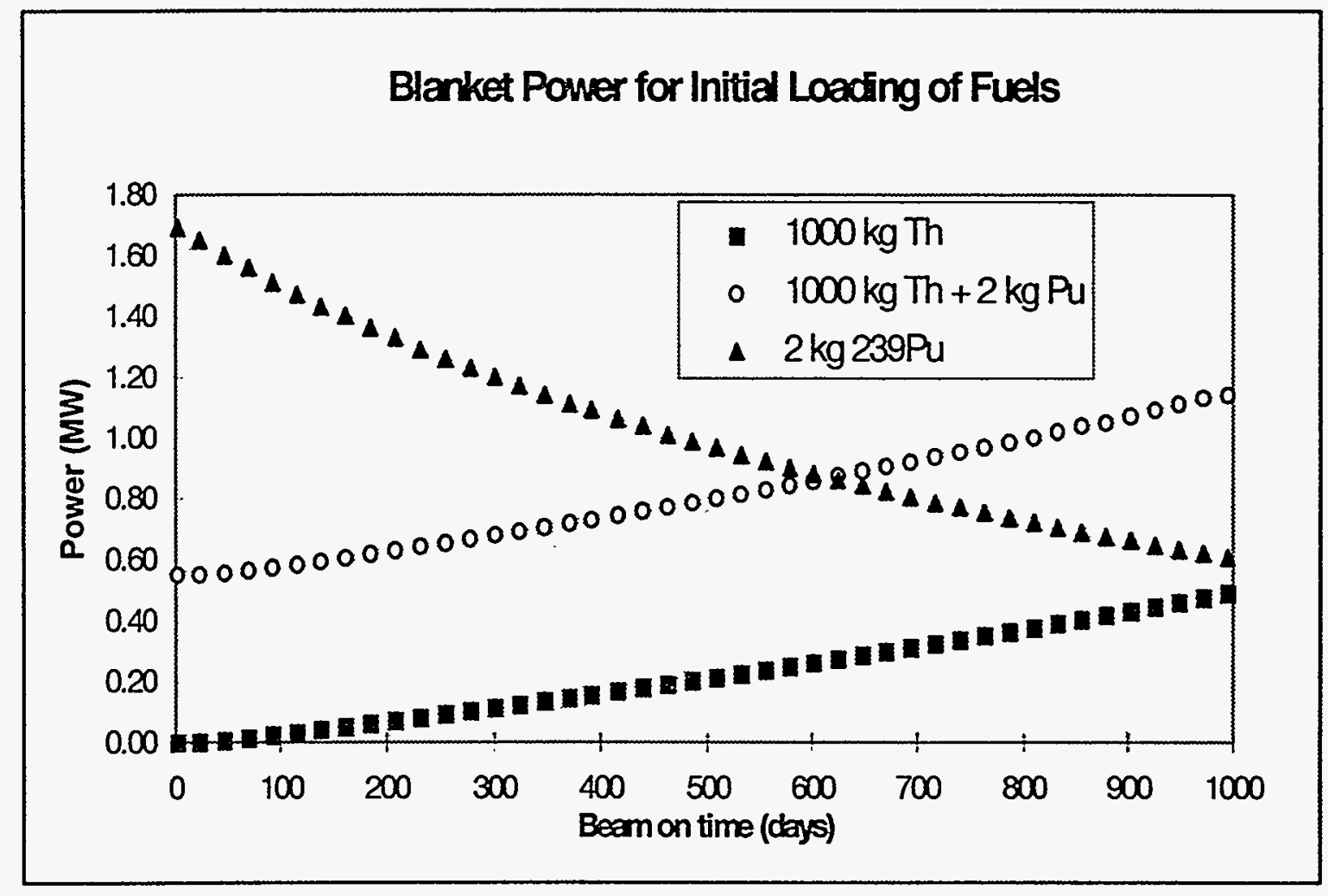

Figure 5 The blanket power for various initial fuel loadings of the blanket. The solid squares are for an initial loading of $1000 \mathrm{~kg}$ of thorium. The open squares is for an initial loading of $1000 \mathrm{~kg}$ of thorium and $2 \mathrm{~kg}$ of ${ }^{239} \mathrm{Pu}$. For comparison, the triangles show the blanket power for $2 \mathrm{~kg}$ of ${ }^{239} \mathrm{Pu}$ alone. 


\section{Conclusion}

This small scale demonstration experiment is a crucial step towards the development of a full scale ADTT system. The experiment addresses many key issues in ADTT technology and will demonstrate the following new technologies:

1. Molten lead neutron production targets

2. Integrated operation of a neutron production target and a subcritical fission blanket assembly.

3. Integral heat exchangers and pumps

4. On-line criticality measurements

5. Helium sparging to remove volatile fission product gases

6. Plutonium burn up

7. Energy production using the thorium/uranium breeding cycle.

\section{References}

1. Nucl. Sci. and Eng. 113 (1993) 287.

2. V.T. Gorshkov et. al, "An Accelerator Based Installation of Small Power with the Lead-Bismuth Coolant", this conference 1994.

3. C. A. Beard et. al, "Flowing Lead Spallation Target Design for Use in an ADTT Experimental Facility Located at LAMPF", this conference 1994.

4. J. J. Park et. al, "Selection of Flowing Liquid Lead Target Structural Materials for Accelerator Driven Transmutation Applications”, this conference, 1994. 